\title{
Quality assurance target for community- based breast cancer screening in China: a model simulation
}

\author{
Lan Yang ${ }^{1,2}$, Jing Wang ${ }^{1}$, Juan Cheng ${ }^{1}$, Yuan Wang ${ }^{1,3}$ and Wenli Lu ${ }^{1,3^{*}}$ (D)
}

\begin{abstract}
Background: We aimed to clarify the feasibility of a community-based screening strategy for breast cancer in Tianjin, China; to identify the factors that most significantly influenced its feasibility; and to identify the reference range for quality control.

Methods: A state-transition Markov model simulated a hypothetical cohort of 100,000 healthy women, the start aged was set at 35 years and the time horizon was set to 50 years. The primary outcome for the model was the incremental cost-utility ratio (ICUR), defined as the program's cost per quality-adjusted life year (QALY) gained. Three screening strategies providing by community health service for women aged 35 to 69 years was compared regarding to different intervals.

Result: The probability of the ICUR being below 20 272USD (i.e., triple the annual gross domestic product [3 GDPs]) per QALY saved was 100\% for annual screening strategy and screening every three years. Only when the attendance rate was $>50 \%$, the probability for annual screening would be cost effective $>95 \%$. The probability for the annual screening strategy being cost effective could reach to 95\% for a willingness-to-pay (WTP) of 2 GDPs when the compliance rate for transfer was $>80 \%$. When $10 \%$ stage I tumors were detected by screening, the probability of the annual screening strategy being cost effective would be up to 95\% for a WTP > 3 GDPs.

Conclusion: Annual community-based breast cancer screening was cost effective for a WTP of 3 GDP based on the incidence of breast cancer in Tianjin, China. Measures are needed to ensure performance indicators to a desirable level for the cost-effectiveness of breast cancer screening.
\end{abstract}

Keywords: Breast cancer, Screening, Cost-effective

\section{Background}

Breast cancer is now the most common cancer in Chinese women, with cases accounting for $12.2 \%$ of all newly diagnosed breast cancers and $9.6 \%$ of all deaths from breast cancer worldwide [1]. There is solid evidence supporting the value of diagnosing cancer early, and Western societies have produced guidelines on early detection $[2,3]$. Indeed, breast cancer screening by populationbased mammography (MAM) has been proven to reduce

\footnotetext{
*Correspondence: luwenli@tmu.edu.cn

'Department of Epidemiology and Health Statistics, School of Public Health, Tianjin Medical University, 22 Qixiangtai Road, Heping District, Tianjin 300070, People's Republic of China

${ }^{3}$ Collaborative Innovation Center of Chronic disease prevention and control,

Tianjin Medical University, Tianjin 300070, China

Full list of author information is available at the end of the article
}

mortality in several randomized trials in developed Western countries $[4,5]$. However, in developing countries, a screening strategy that combines clinical breast examination (CBE) and breast ultrasonography (USG) may be a more acceptable approach [6, 7].

There is no nationwide screening program for breast cancer in China at present [1], although population-based studies of CBE combined with diagnostic USG, MAM, or both are currently in progress $[1,8]$. Local governments have also sponsored community-based breast cancer screening programs in several urban cities despite doubts about the efficacy of CBE for early detection in diverse Chinese populations. Interestingly, a population-based study of these breast cancer screening programs provided good performance results, with a sensitivity and specificity 
of $70 \%$ and $90 \%$, respectively [9]. Nevertheless, breast cancer screening, especially when using CBE, may not be as effective in clinical settings as it is in trial settings [10].

In Tianjin, the fourth largest city in China in terms of urban population, initial breast cancer screening is provided at community health services without the support of MAM or USG services from 2009.CBEs are done by trained health care providers funded by the local government as part of the basic public health service package. Women determined by their primary physicians to have a lesion that is suspicious or highly suggestive of a malignancy are then referred for further diagnostic tests and treatment, but these are not part of the basic public health service package and must be paid by patients or their medical insurance.

The government and public have high expectations of community health services to protect women's health by detecting breast cancer early. However, community health services may not always be able to fulfill this role because of their limited diagnostic capacity and the shortage of doctors compared with the considerable number of women eligible for screening [11]. This is compounded by the fact that there has been no report on the feasibility of the current breast cancer screening program.

The primary aim of a breast screening program should be to reduce mortality from breast cancer through early detection. Unfortunately, it would take decades to confirm the effectiveness of such a screening program based on mortality indicators alone. By contrast, quality assurance allows the use of alternative performance indicators for quality control and evaluation [12-14]. There is a growing need to develop approaches that reflect the relationships between performance indicators and the feasibility of a screening strategy. Such an approach should help determine those factors that should be considered most important in practice, and should help set reasonable goals for the relevant indicators.

A decision-analytic model was used in the current study to predict the feasibility of a community-based breast cancer screening strategy in China. In addition, a sensitivity analysis approach was used to identify the relevant factors that significantly influenced the feasibility of such screening in community health services and to identify the optimum control ranges of those factors.

\section{Methods}

\section{Community-based screening strategy}

In Tianjin, China, a community-based breast cancer screening program for women aged 35-69 years has been conducted for a seven-year period using CBE (Fig. 1). No inter-screening interval period has been clearly defined. When women have a positive CBE result, they are advised to undergo diagnostic USG or MAM.

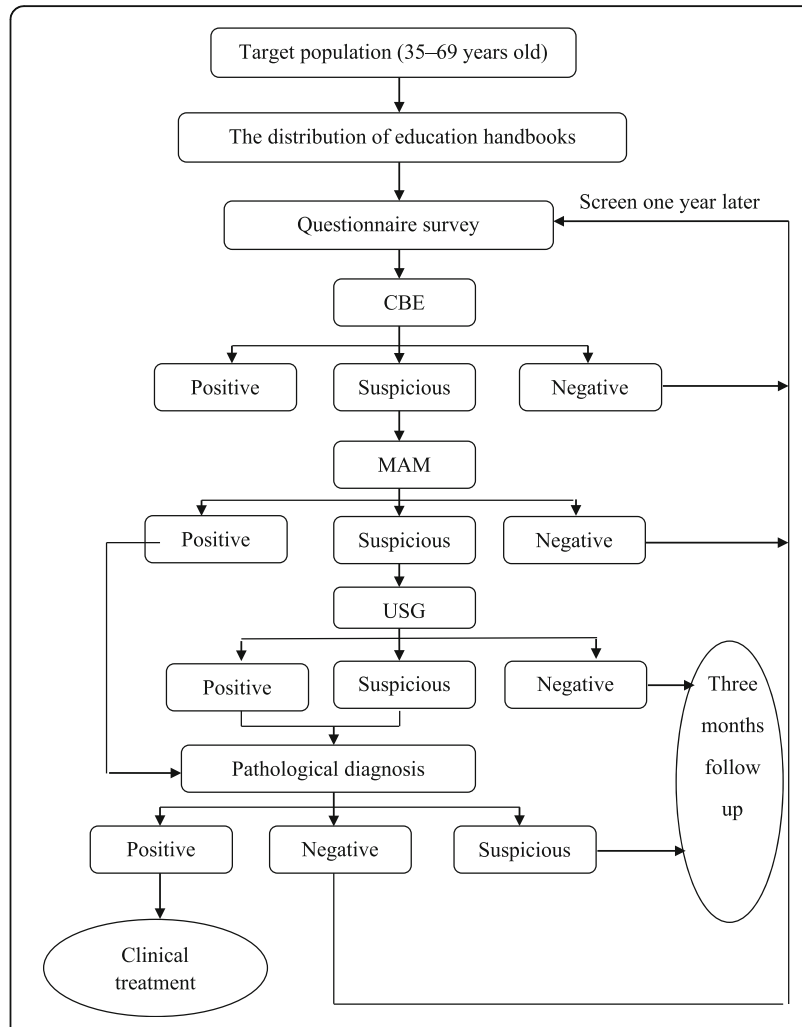

Fig. 1 The Screening Flow Chart (Conventional Version)

\section{Markov decision tree}

A state-transition Markov model was developed that consisted of two linked modules: (a) a breast cancer progression model, and (b) a screening model. The breast cancer progression model consisted of eight main health states: well; ductal carcinoma in situ (DCIS); the four invasive cancer stages defined by the American Joint Committee on Cancer (stage I-IV); and two death states, including death from breast cancer and death from causes unrelated to breast cancer. Women who were not detected as having breast cancer could present with signs and symptoms of breast cancer and could progress through each cycle. It was assumed that breast cancer deaths could occur only among women with stage IV disease, except when death was from natural causes. The transition probabilities from health status to breast cancer was calculated with age specified incidence and afterwards stage distribution in order to assign the stage in which cancer was detected (by screening or symptoms). Age-specific death rate from all causes and the age-specific death rate from breast cancer were used to estimate the transition probabilities from health or breast cancer to death (Table 1). The probabilities of stage progression were taken from a previous study in Chinese women [15]. (b) The screening model was based on whether in a screening year, women went into the model and accepted CBE, and whether women with 
Table 1 Clinical and cost parameter estimates for the base case and sensitivity analyses

\begin{tabular}{|c|c|c|c|c|}
\hline Parameter & & & & Ref. \\
\hline The distribution of invasive Breast Cancer stages & Screen & No screen & Distribution & {$[43,44]$} \\
\hline Stage I & 0.360 & 0.203 & \multirow{5}{*}{$\begin{array}{l}\text { Dirichlet } \\
\text { [15] }\end{array}$} & \\
\hline Stage ॥ & 0.490 & 0.541 & & \\
\hline Stage III & 0.144 & 0.237 & & \\
\hline Stage IV & 0.006 & 0.019 & & \\
\hline Screen method test characteristics & Sensitivity & Specificity & & \\
\hline CBE & $0.431(0.335-0.528)$ & $0.994(0.994-0.995)$ & \multirow{3}{*}{$\begin{array}{l}\text { Uniform } \\
\text { [15] }\end{array}$} & \multirow[t]{3}{*}{ [18] } \\
\hline A series of $C B E, M A M$ and ultrasound connection & $0.330(0.238-0.422)$ & $0.999(0.999-1.000)$ & & \\
\hline A series of CBE and MAM connection & $0.360(0.256-0.454)$ & $0.999(0.999-1.000)$ & & \\
\hline \multicolumn{3}{|l|}{ Stage progression transition probabilities } & & [15] \\
\hline Stage I-IV & 0.01 & & \multirow{3}{*}{$\begin{array}{l}\text { Invariant } \\
{[15]}\end{array}$} & \\
\hline Stage II-IV & 0.08 & & & \\
\hline Stage III-IV & 0.21 & & & \\
\hline Compliance rate & $0.5-1$ & & $\begin{array}{l}\text { Uniform } \\
\text { [15] }\end{array}$ & [18] \\
\hline Attend rate & $0.3-1$ & & $\begin{array}{l}\text { Uniform } \\
\text { [15] }\end{array}$ & \\
\hline Transition probabilities of breast cancer(Rate per 100,000 women) & All-cause mortality & & Breast cancer mortality & \\
\hline $35-$ & 53.86 & & 3.78 & [17] \\
\hline $40-$ & 95.25 & & 6.90 & \\
\hline $45-$ & 149.34 & & 12.66 & \\
\hline $50-$ & 212.43 & & 16.57 & \\
\hline $55-$ & 348.31 & & 22.74 & \\
\hline $60-$ & 604.84 & & 23.49 & \\
\hline $65-$ & 1030.55 & & 23.95 & \\
\hline 70- & 2036.08 & & 25.86 & \\
\hline 75- & 3783.51 & & 31.57 & \\
\hline $80-$ & 6997.94 & & 40.36 & \\
\hline$>85$ & $13,602.90$ & & 48.85 & \\
\hline Cost components $^{\mathrm{a}}$ & Cost & & & \\
\hline Management cost and cost for CBE & $\$ 4.3$ & & & [20] \\
\hline \multicolumn{5}{|l|}{ Cost of evaluating abnormal CBE } \\
\hline MAM & $\$ 29.0$ & & & \multirow[t]{3}{*}{ [20] } \\
\hline USG & $\$ 10.2$ & & & \\
\hline Cost of biopsy & $\$ 174.3$ & & & \\
\hline Treatment and follow-up & Treatment cost & & Follow-up cost & \\
\hline DCIS & $\$ 1607.2$ & & $\$ 1712.7$ & \multirow[t]{5}{*}[21,22]{} \\
\hline Stage I & $\$ 1940.7$ & & $\$ 4022.8$ & \\
\hline Stage II & $\$ 1960.1$ & & $\$ 5653.7$ & \\
\hline Stage III & $\$ 1902.9$ & & $\$ 6481.7$ & \\
\hline Stage IV & $\$ 1566.7$ & & $\$ 4584.5$ & \\
\hline
\end{tabular}

Abbreviations: CBE; Clinical breast examination, MAM; Mammography, USG; Ultrasonography, DCIS; Ductal carcinoma in situ ${ }^{\mathrm{a}}$ Exchange rate $6.8858 \mathrm{RMB}=1$ US Dollar 
positive or suspicious CBE results underwent MAM. Women with suspicious MAM results also underwent a supplementary USG examination. Those with positive results on MAM and USG would either receive breast biopsy or undergo prompt surgery. Women who had positive MAM results but negative USG results, and women who had suspicious biopsy results would receive an extra follow up USG after three months. Women who were not detected as having breast cancer could present with signs and symptoms of breast cancer and could progress through each cycle (clinical detected).

During the simulation, one-, two-, and three-year intervals were compared because the inter-screening interval was not clearly defined in clinical practice. The model tracked a cohort of 100,000 women, without breast cancer, aged 35 years. The timeframes for exposure to screening was to 69 years old. The time horizon was set at 50 years since the estimate survival probability was less than $10 \%$ for Chinese women at 85 year of age and the mortality was not available for older age group.

\section{Key parameter estimates}

Stage progression transition probabilities referred to Wong et al. [15]. Age-specific breast cancer incidence was extracted from Chinese Cancer Registry Annual Report 2011 [16]. All cause-mortality was referred to the official 2012 statistical data for China [17]. The sensitivity and specificity for different screen method get from a breast cancer screening study [18] in which 30,935 women enrolled in five cities and 102 breast cancer detected. Key parameter estimates are summarized in Table 1.

Assumption of performance indicators considered as input parameters included stage distribution, attendance rate, and compliance rate for referral for diagnostic tests. The indicators were extracted from the results of a community-based breast cancer screening programs [19].

We calculated quality-adjusted life years (QALYs), which weighted the time spent in each health state by health related quality-of-life weightings from the Hong Kong model [15]. A QALY of 1.0 was defined as "well without breast cancer," but QALYs of $<1.0$ were ranked by cancer stage, with QALYs of 0.95, 0.9, 0.8, 0.7, and 0.3 corresponding to stages DCIS, I, II, III, and IV, respectively.

\section{Costs}

Four major categories were included for the following direct medical costs (Table 1): (1) the cost to community health services; (2) the cost of evaluating abnormal CBE results, including the costs of ultrasound and mammography; (3) the cost of biopsy [20]; and (4) the cost of treating invasive cancer and DCIS (primary treatment) include inpatient cost and outpatient cost. The outpatient cost includes follow-up screening test, radiotherapy, chemotherapy and targeted Therapy and so on in the next year after primary treatment $[21,22]$.

\section{Model outcomes}

The primary outcome of the model was the incremental cost-utility (ICUR), which was defined as the program's cost per QALY gained. Model outcomes also included the number of deaths from breast cancer, the number of deaths from other causes, person years of survival adjusted for health quality, and person years of survival with breast cancer (the life years and lifetime costs). The cost-effectiveness threshold: highly cost-effective (less than 1 GDP per capita), cost-effective (1-3 times GDP per capita; 6751 USD -20 272USD), and not cost-effective (more than 3 times GDP per capita) [23]. Future costs and QALYs were discounted at an annual rate of 3\% from a societal perspective. The comparator was set as the null scenario of no screening.

\section{Sensitivity analysis}

A Monte Carlo simulation was done with 1000 runs to select values at random from appropriate probabilistic distribution [15] model parameters. Based on the simulation results, cost-effectiveness acceptability curves were presented to the uncertainty in the ICUR caused by variations in parameters such as the attendance, compliance with referral for diagnostic tests, incidence (Please see Additional file 1: Figure S1) and positivity for stage I disease. One-way sensitivity analyses were performed to assess the effects of changes in a given parameter on the model's outcomes. Expected Value of Partial Perfect Information (EVPPI) was calculated. The acceptability of willingness-to-pay (WTP) triple the annual gross domestic product (i.e., 3 GDPs) per capita per QALY was compared between different cut-off points for the performance indicators.

\section{Results \\ Cost-effectiveness}

In the model simulation, annual community-based breast cancer screening from age 35 years to 69 years would avert approximately 177 deaths from breast cancer per 100,000 women compared with no screening (Table 2). In addition, the screening model would detect 1.86 times more DCIS cases would die of other causes compared with the no screening model (e.g., 164 vs. 88 cases per 100,000 women). Compared with no screening, the community-based breast cancer screening would also save approximately 1583 discounted QALYs per 100,000 women screened, equivalent to an average increase in life expectancy of 5.25 years per woman with breast cancer, but for an increase in cost by 10.3 million dollars. Compared with the annual CBE strategy, less frequent screening every two or three years led to small decreases of $4 \%$ 
Table 2 Health states and cumulative number for a single simulated cohort of 100,000 Chinese women aged 35 years at the last year of simulation (50th year)

\begin{tabular}{|c|c|c|c|c|c|c|c|c|c|c|c|c|}
\hline $\begin{array}{l}\text { Screen } \\
\text { strategy }\end{array}$ & Well & DCIS & $\begin{array}{l}\text { Stage } \\
1\end{array}$ & Stagell & $\begin{array}{l}\text { Stage } \\
\text { III }\end{array}$ & $\begin{array}{l}\text { Stage } \\
\text { IV }\end{array}$ & $\begin{array}{l}\text { Die } \\
\text { of } B C\end{array}$ & $\begin{array}{l}\text { BC death } \\
\text { avoided (\%) }\end{array}$ & $\begin{array}{l}\text { No } B C \text { die of } \\
\text { other causes }\end{array}$ & $\begin{array}{l}\text { DCIS die of } \\
\text { other causes }\end{array}$ & $\begin{array}{l}\text { Invasive BC die of } \\
\text { other causes }\end{array}$ & $\begin{array}{l}\text { Screen- } \\
\text { detected }\end{array}$ \\
\hline $\begin{array}{l}\text { No } \\
\text { screen }\end{array}$ & 33,068 & 58 & 240 & 184 & 27 & 107 & 2187 & - & 63,017 & 88 & 1024 & - \\
\hline $1 / 1$ year & 33,097 & 100 & 266 & 172 & 25 & 102 & 2010 & 8.8 & 62,986 & 164 & 1078 & 1698 \\
\hline $1 / 2$ years & 33,097 & 79 & 251 & 173 & 25 & 102 & 2090 & 4.6 & 62,987 & 127 & 1069 & 903 \\
\hline $1 / 3$ years & 33,097 & 72 & 246 & 174 & 25 & 102 & 2118 & 3.3 & 62,985 & 114 & 1067 & 580 \\
\hline
\end{tabular}

Abbreviations:DCIS; Ductal carcinoma in situ, $B C$; Breast cancer

and $8 \%$ in the marginal QALYs, respectively, with corresponding total cost decreases of only $5 \%$ and $7 \%$. The ICUR was 8137.29 of every two years screening strategy compare to every three years screening strategy that was higher than the other two ICURs (7075.77 and 8047.96; Table 3).

\section{Sensitivity analysis}

Figure 2 shows the cost-effectiveness acceptability curves based on different WTP values (the ceiling costeffectiveness ratio). The probability of the ICUR being below 3 GDPs per QALY saved was 100\% for two nondominated options. The annual screening strategy was also acceptable when the WTP was $>2$ GDPs per QALY.EVPPI analysis returned a threshold of zero for most model parameters with a WTP threshold of 3 GDP. This finding suggests that although there is uncertainty around model parameter estimates, reducing this parameter uncertainty is not likely to change the decision about whether routine breast cancer screening should be recommended.

\section{CEAC for variation in the age-specific cancer incidence}

When we used U.S. age-specific cancer incidence [24, 25] or age-specific cancer incidence in rural Chinese areas [17] (Table 1) as the input parameters, the cost-effectiveness rankings did not change; however, the probability of it being acceptable was different by area (Fig. 3a). When the incidence of the U.S. population was used in the screening simulation, the probability of the annual screening strategy being cost effective was $100 \%$ at a WTP threshold of 1 GDP. But, when the incidence was substituted for urban and rural Chinese areas, the probabilities were $40 \%$ and $0 \%$, respectively.

\section{CEAC for variation in the attendance rate}

The attendance rate had a substantial influence on the cost-effectiveness of community-based breast cancer screening. When the value was set to $30 \%$, the probability of the annual screening strategy being cost effective was $<50 \%$ at the 3 GDP level of WTP. When the attendance rate was $>50 \%$, the probability for the annual screening strategy being cost effective was $>95 \%$ at the 3 GDP level of WTP (Fig. 3b).

\section{CEAC for variation in the compliance rate for transfer}

When compliance with transfer was set at $>50 \%$, the probability for annual screening being cost effective was about $95 \%$ at the 3 GDP level of WTP. But, the probability for annual screening strategy being cost effective was $>95 \%$ at the 2 GDP level of WTP only when the compliance rate was set at $>80 \%$ (Fig. $3 \mathrm{c}$ ).

\section{CEAC for variation in detection of earlier stage of tumor}

When $10 \%$ of stage I tumors were detected on the screening simulation, the probability of the annual screening strategy being cost effective was $>95 \%$ for WTP levels $>3$ GDPs. When $20 \%$ of stage I tumors were detected, however, the probability of the annual screening strategy being cost effective was $>95 \%$ at the 2 GDP level of WTP (Fig. 3d).

\section{Discussion}

In this study, we evaluated the effectiveness of an ongoing, community-based, breast cancer prevention program offered by community health services in Tianjin, an urban area in China. The cost-effectiveness analysis showed that the ongoing costs of this screening program

Table 3 The cost-utility analysis of different screening strategy

\begin{tabular}{llllll}
\hline $\begin{array}{l}\text { Screening } \\
\text { Strategy }\end{array}$ & $\begin{array}{l}\text { Utility } \\
\text { (QALY) }\end{array}$ & $\begin{array}{l}\text { Cost } \\
\text { (million USD) }\end{array}$ & $\begin{array}{l}\text { ICUR }^{\text {a }} \\
\text { (USD/QALY) }\end{array}$ & $\begin{array}{l}\text { ICUR }^{\text {b }} \\
\text { (USD/QALY) }\end{array}$ & $\begin{array}{l}\text { CU } \\
\text { (USD/QALY) }\end{array}$ \\
\hline No screen & 2388195 & 96.08 & - & - & 40.23 \\
$1 / 3$ years & 2388782 & 100.23 & 7075.77 & 7075.77 & 41.96 \\
$1 / 2$ years & 2389034 & 102.28 & 7394.60 & 8137.29 & 42.81 \\
$1 / 1$ year & 2389778 & 108.27 & 7701.68 & 8047.96 & 45.30 \\
\hline
\end{tabular}

Abbreviations: CU Cost/Utility, ICUR incremental cost-utility ratio, QALY quality-adjusted life-year

ICUR $^{\mathrm{a}}$ based on the no screen strategy; ICUR ${ }^{\mathrm{b}}$ based on the previous screening strategy 


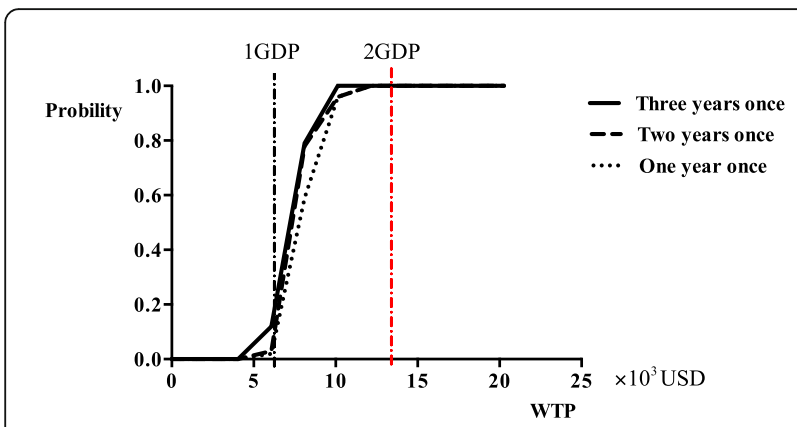

Fig. 2 The acceptable curves for different schemes

were lower than the recommended threshold of triple the GDP per capita per QALY, and that they were cost effective regardless of whether a 1- or 3-year screening interval was used. In addition, it was shown that the annual screening strategy would still be cost effective at the triple the GDP per capita per QALY threshold when the age-specific cancer incidence was as low as that in rural areas. If the anticipated reduction in breast cancer mortality is to be achieved in reality, the following targets will probably need to be met: an attendance rate of at least $50 \%$, compliance with transfer of at least $50 \%$, and an incidence of stage I tumor of at least $10 \%$.

Although the effectiveness of population-based breast cancer screening is of paramount importance, costeffectiveness analyses are also necessary and play an important role in decision-making for public health policy. A conventional community-based screening strategy for the early diagnosis of breast cancer has been available in Tianjin China since 2005, and there are no data regarding long-term outcomes. The results of the current costeffectiveness analysis, and the probabilistic approach in particular, show that screening at a one-year interval offers cost-effective when compared with no screening. Indeed, the acceptability curve of the Monte Carlo costeffectiveness plane suggests that, versus no screening, the probability was $80 \%$ for cost effectiveness in the parallel mode given a 2 GDPs per QALY ceiling value with the screening distribution of stage I cancer being $40 \%$. Given that the shortage of human resources in primary care may produce a bottleneck to annual breast cancer screening [26, 27], our data indicate that screening every three years may be a reasonable alternative. In current study comparison only was made between strategies with different frequency and with only CBE as screening test. Strategies with different screening start-age and the other combinations of screen tests were not studied in this model simulation. Age distribution in China was normal with one age peak at 45-49 years, displaying differences from USA and Chinese American with two age peaks [28]. Chinese women present with breast cancer at an earlier age. Kwong et al. reported that $17.6 \%$ of the
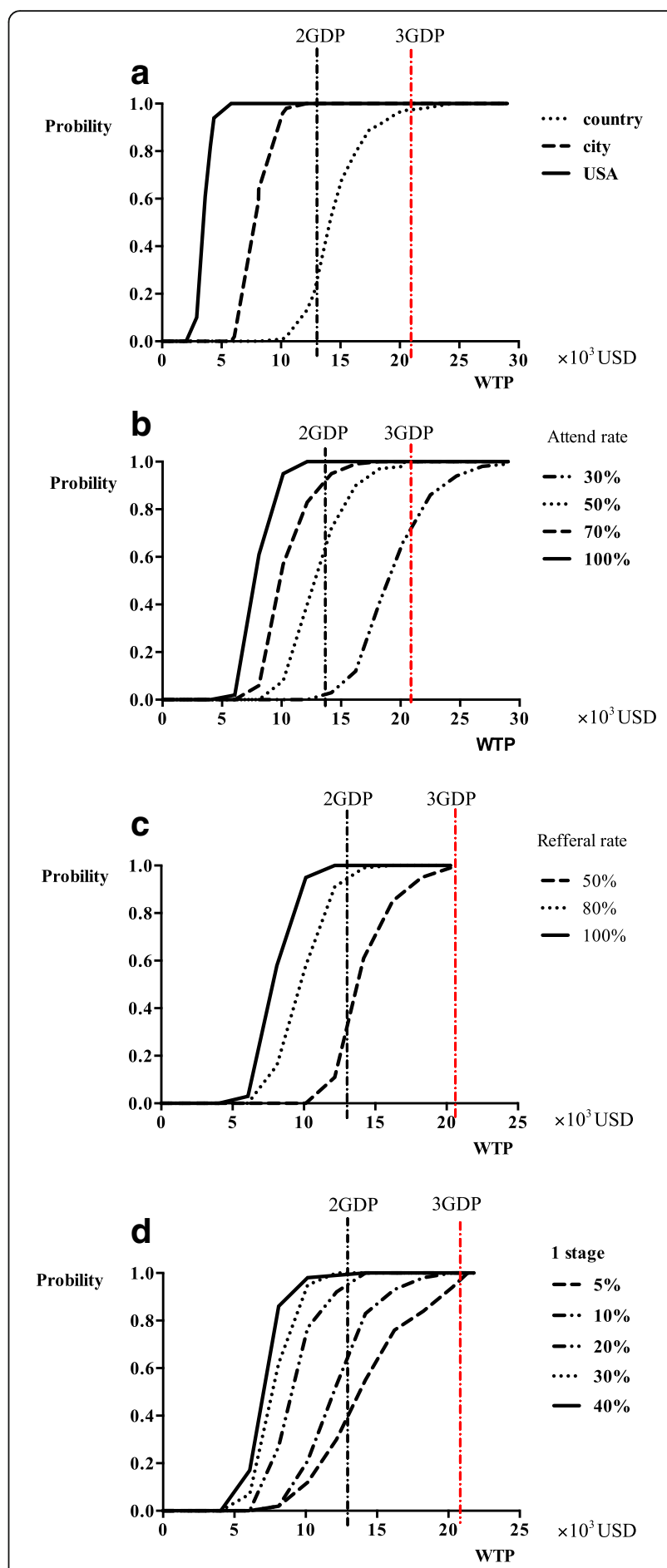

Fig. 3 a The acceptable curves for different breast cancer incidence. b The acceptable curves for different attend-rate. c The acceptable curves for referral rate. $\mathbf{d}$ The acceptable curves regarding to different proportions of stage 1 tumor assumed

women were younger than 40 years old, and age distribution was significantly different from women in the SEER database [29]. Chinese Anti-Cancer Association recommended the starting age as 40 and the local government 
sponsored the basic public health service package including CBE for women aged 35-69 years. The additional comparisons show that screening strategies of a later starting age at 40 were more cost-saving compared with that with a younger starting age at 35 and could be more preferable for regions with limited human resources (Please see Additional file 1: Table S1).

It will only be many years after the introduction of a breast screening program that any potential reductions in breast cancer mortality can be expected [30]. In the meantime, it is important that interim outcome measures are monitored to determine whether or not the program is performing satisfactorily. One suitable performance indicator that determines the outcome of a screening program is the attendance rate. The recommended targets for attendance were fulfilled in two previous national breast cancer screening projects in the urban areas of Chengdu (49.0\%) and Mianyang (52.1\%) in 2008 [31]. However, a cross-sectional study in the same area showed a much lower attendance rate (31.9\%). An equally disappointing participation rate $(21.7 \%)$ was reported by the 2010 China Chronic Disease and Risk Factor Surveillance System, which included data from both urban and rural areas [32]. Comprehensive and prioritized strategies are therefore needed to improve breast cancer screening participation and ensure its cost-effectiveness.

Women with positive CBE results were advised to undergo a combination of USG and MAM for diagnosis, even though these were not covered by the community breast cancer screening package. Compliance with these further investigations also affected the efficacy of the screening strategy. It was identified, that to ensure a probability of $95 \%$ for cost effectiveness of the annual screening strategy at the 3 GDP level of WTP, the quality assurance target would need to be $50 \%$. In another breast cancer screening program with a similar design in Qibao Shanghai, about 30\% of participants who should have undergone imaging did not [33]. It is important to educate, train, and motivate referring clinicians in community health services of the importance of their role in enabling women to make informed decisions [34, 35].

Finally, CBE was introduced as the initial method of screening for breast cancer in our community-based strategy [36, 37]. Apart from the attendance and transfer compliance rates, the performance of $\mathrm{CBE}$ should also be considered relevant to the overall efficacy of the program [36], especially given that measures of screening accuracy are particularly important interim indicators of effectiveness [4]. In our study, we considered the rate of detection of earlier stage tumors to be a suitable indicator of screening efficacy, rather than the overall rate of cancer detection or the screening sensitivity. The annual screening strategy remained cost effective when detection rate of stage I tumor was assumed even lower $(10 \% / 20 \%)$ and the total proportion of other stages was set at 90\%/ $80 \%$ with each proportion for stage II to IV simulated randomly change. Similar screening that relied on initial CBE in Shanghai indicated that a detection proportion of $29 \%$ for stage I tumors would be acceptable at a 3 GDP level of WTP [33]. The performance of CBE, however, can only be assured when the involved clinical staff are sufficiently well trained and have appropriate knowledge of the principles of breast cancer diagnosis, management, and screening.

As a major limitation of the current study, it should be noted that any Markov decision model should be validated using external empirical data. However, the screening program still requires long-term follow up to provide this empirical data. To mitigate this, we took care to calibrate the analysis to fit local empirical observations, and most of the parameters assigned to the Markov cycle tree were derived from previous screening program [9]. The Monte Carlo simulation was also done with 1000 runs to select values at random from appropriate probabilistic distributions of model parameters. Three performance indicators for quality assurance were identified in the current study using Monte Carlo simulation, and these might be useful as initial measures of program quality. Moving forward, continuous follow up of the target population is needed over an extended period of time to facilitate a long-term evaluation of its effectiveness [38]. Over-diagnosis was always an important issue when a screening strategy was discussed. However, only over-diagnosis of DCIS was evaluated in current study. The screen-detected breast cancer cases had probability dying of other cause before being clinical occurrences that could be evaluated only when sojourn time was available. Arrospide, A et al. reported that $4 \%$ of screen-detected cancers were over-diagnosed [39]. Another study presented that one breast cancer death prevented for about every three over-diagnosed cases identified and treated [40]. When a screening program was discussed, both benefits and harms should be taken into accounted. It should also be noted that the time horizon was set at 50 years in current study and for women elder than 85 , the model is not able to predict whether death will be due to $\mathrm{BC}$ or other causes that might influence the effectiveness of screening, but it will not cause significant changes. In addition, Markov cohort model was used to compare breast cancer screening strategies with different screening intervals. One important limitation should be noted was Markov cohort model couldn't track individual patient histories which resulted in the fail to specify the benefit of screening over no screening in individual view. Another useful technique discrete event simulation modeling can track individual patient histories, such that each individual in the economic model can carry a large amount of information which can affect their future treatment options, 
risk of events and prognosis over time. However, the utilization of discrete event simulation required more data. Due to the lack of age distribution of preclinical phase onset and its mean duration, Markov cohort model was chosen over discrete event simulation. It should be mentioned that Markov cohort model might resulted better estimates for the decision making of the health care resource allocation [41, 42].

\section{Conclusion}

Chinese government and public have high expectations of community health services to protect women's health by detecting breast cancer early. However, community health services may not always be able to fulfill this role. There is a growing need to develop approaches that reflect the relationships between performance indicators and the feasibility of a screening strategy. Our research suggested that annual community-based breast cancer screening was cost effective for a WTP of 3 GDP based on the incidence of breast cancer in urban city Tianjin, China. Measures are needed to ensure performance indicators to a desirable level for the the cost-effectiveness of breast cancer screening.

\section{Additional file}

Additional file 1: Figure S1. Shows the age-specific incidence rate of breast cancer in USA, rural and urban area of China, while Table S1. includes the information of cost-utility analysis of different screening strategy among 40-69 years old women. (DOCX $28 \mathrm{~kb}$ )

\section{Abbreviations}

CBE: Clinical breast examination; CU: Cost/Utility; DCIS: Ductal carcinoma in situ; GDP: Gross domestic product; ICUR: Incremental cost-utility ratio; MAM: Mammography; QALY: Quality-adjusted life year; USG: Ultrasonography; WTP: Willingness-to-pay

\section{Acknowledgements}

We thank Dr. Robert Sykes (www.doctored.org.uk) for providing editorial services.

\section{Funding}

This study was supported by the National Natural Science Foundation (Grants No. 81301799). The funders had no role in the study concept, study design, data analysis, interpretation, or reporting of the results. The authors had full control of the data and information submitted for publication.

\section{Availability of data and materials}

The data analyzed during this study are included in this published article and its supplementary information files.

\section{Authors' contributions \\ LY: Constructing and modifying the estimate model, searching associated parameters, drafting article; JW: Searching associated parameters, drafting article, modifying the format of article; JC: Searching associated parameters and modifying the format of article; YW: Modifying model, drafting and revising article; WLL: Planning, conducting work, modifying model, interpretation of data, drafting and revising article. All authors read and approved the final manuscript.}

\section{Ethics approval and consent to participate}

All data were extracted from published articles and only population level data were included in this study, for this type of study formal consent is not required.
Consent for publication

No applicable.

\section{Competing interests}

The authors declare that they have no competing interests.

\section{Publisher's Note}

Springer Nature remains neutral with regard to jurisdictional claims in published maps and institutional affiliations.

\section{Author details}

${ }^{1}$ Department of Epidemiology and Health Statistics, School of Public Health, Tianjin Medical University, 22 Qixiangtai Road, Heping District, Tianjin 300070, People's Republic of China. ${ }^{2}$ Tianjin Binhai New Area Tanggu Center for Disease Control and Prevention, Tianjin 300451, China. ${ }^{3}$ Collaborative Innovation Center of Chronic disease prevention and control, Tianjin Medical University, Tianjin 300070, China.

Received: 14 January 2017 Accepted: 26 February 2018

Published online: 07 March 2018

\section{References}

1. Fan L, Strasser-Weippl K, Li JJ, St Louis J, Finkelstein DM, Yu KD, Chen WQ, Shao ZM, Goss PE. Breast cancer in China. Lancet Oncol. 2014;15(7):e279-89.

2. Hartnett $E$. Impact of changes to breast cancer screening guidelines on healthcare providers and patients. Clin J OncolNurs. 2016;20(2):203-5.

3. Oeffinger KC, Fontham ET, Etzioni R, Herzig A, Michaelson JS, Shih YC, Walter LC, Church TR, Flowers CR, Lamonte SJ. Breast cancer screening for women at average risk: 2015 guideline update from the American Cancer Society. JAMA. 2015;314(15):1599-614.

4. Marmot MG, Altman DG, Cameron DA, Dewar JA, Thompson SG, Wilcox M. The benefits and harms of breast cancer screening: an independent review. Br J Cancer. 2013;108(11):1778-86.

5. Myers ER, Moorman P, Gierisch JM, Havrilesky LJ, Grimm LJ, Ghate S, Davidson B, Mongtomery RC, Crowley MJ, Mccrory DC. Benefits and harms of breast cancer screening: a systematic review. JAMA. 2015;314(15):1615-34.

6. Alfoheidi M, Almansour MM, Ibrahim EM. Breast cancer screening: review of benefits and harms, and recommendations for developing and low-income countries. Med Oncol. 2013;30(2):1-15.

7. Health Quality Ontario. Ultrasound as an adjunct to mammography for breast cancer screening: a health technology assessment. Ont Health Technol Assess Ser. 2016:16(15):1-71.

8. Dai H, Yan Y, Wang P, Liu P, Cao Y, Xiong L, Luo Y, Pan T, Ma X, Wang J. Distribution of mammographic density and its influential factors among Chinese women. Int J Epidemiol. 2014;43(4):1240-51.

9. Huang Y, Kang M, Li H, Li JY, Zhang JY, Liu LH, Liu XT, Zhao Y, Wang Q, Li CC. Combined performance of physical examination, mammography, and ultrasonography for breast cancer screening among Chinese women: a follow-up study. Curr Oncol. 2012;19(Suppl 2):22-30.

10. Elmore JG, Armstrong K, Lehman CD, Fletcher SW. Screening for breast cancer. JAMA. 2005;293(10):1245-56.

11. Zhou W, Dong Y, Lin X, Lu W, Tian X, Yang L, Zhang X. Community health service capacity in China: a survey in three municipalities. J EvalClinPract. 2013;19(1):167-72

12. Perry N, Broeders M, de Wolf C, Tornberg S, Holland R, von Karsa L: European guidelines for quality assurance in breast cancer screening and diagnosis. Fourth edition-summary document. Ann Oncol 2008, 19(4):614-622.

13. Kiderlen M, Ponti A, Tomatis M, Boelens PG, Bastiaannet E, Wilson R, Velde CJHVD, Audisio RA. Variations in compliance to quality indicators by age for 41,871 breast cancer patients across Europe: a European Society of Breast Cancer Specialists database analysis. Eur J Cancer. 2015:51(10):1221-30.

14. Mackenzie A, Warren LM, Wallis MG, Given-Wilson RM, Cooke J, Dance DR, Chakraborty DP, Halling-Brown MD, Looney PT, Young KC. The relationship between cancer detection in mammography and image quality measurements. Phys Med. 2016;32(4):568-74.

15. Wong IO, Kuntz KM, Cowling BJ, Lam CL, Leung GM. Cost effectiveness of mammography screening for Chinese women. Cancer. 2007;110(4):885-95.

16. Hao J, Zhao P, Chen WQ. Chinese cancer registry annual report 2011. 1st ed. Beijing: Military Medical Science Press; 2011.

17. Ministry of Health of the People's Republic of China. China health statistical yearbook 2012. 1st ed. Beijing: Peking Union Medical College Press; 2012. 
18. Li WQ, Li R, Liu PF, H YB. Discussion of breast cancer screening model in China[J]. Chinese Journal of Epidemiology. 2016;37(7):1039-43.

19. Yu HY, Li WP, Qi W, Xiu Z, Lian ZQ. Evaluation of breast screening in city women form 2006 to 2011. Chin J Cancer Prev Treat. 2013;20(12):894-7.

20. National Health and Family of the People'S republic of China. Project management of rural women "Two Cancers" in 2010 http://www.moh.gov. cn/fys/s3581/201007/02a20b251ac646f2896dbc0b71a2cf92.shtml. Accessed 10 July 2015.

21. LV LL, Shao ZM, Yang WT, Chen YB, Chen W. Analysis on treatment cost of breast cancer patients with different clinical stages. Chinese Health Resources. 2011;14(3):154-7.

22. Yang L, Gao Y, Li W, Wang Y, Lu WL. Estimate and control of the cost of community-based breast cancer screening. Chinese General Practice. 2015; 18(34):4179-83.

23. Momcilovic B. Macroeconomics and health: investing in health for economic development. Report of the commission on macroeconomics and health. RevistaPanamericana De SaludPública. 2002;12(48):143-4.

24. CE DS, Fedewa SA, Goding Sauer A, Kramer JL, Smith RA, Jemal A. Breastcancer statistics, 2015: convergence of incidence rates between black and whitewomen. CA Cancer J Clin. 2016;66(1):31-42.

25. Surveillance, Epidemiology, And end results (SEER) program. SEER public use CD-ROM program. Bethesda, Md: National Cancer Institute, Division of Cancer Prevention and Control, Surveillance Program, Cancer Statistics Branch; 1973-2002.

26. Yang J, Guo A, Wang Y, Zhao Y, Yang X, Li H, Duckitt R, Liang W. Human resource staffing and service functions of community health services organizations in China. Ann Fam Med. 2008;6(5):421-7.

27. Anderson BO, Shyyan R, Eniu A, Smith RA, Yip CH, Bese NS, Chow LW Masood S, Ramsey SD, Carlson RW. Breast cancer in limited-resource countries: an overview of the Breast Health Global Initiative 2005 guidelines. Breast J. 2006;12(Suppl1):S3-S15.

28. Chen C, Sun S, Yuan JP, Wang YH, Gao TZ, Zheng HM, et al. Characteristics of breast cancer in Central China, literature review and comparison with USA. Breast. 2016;30:208-13.

29. Kwong A, Cheung P, Chan S, Lau S. Breast cancer in Chinese women younger than age 40: are they different from their older counterparts? World. 2008;32(12):2554-61.

30. Oestreicher N, Lehman CD, Seger DJ, Buist DS, White E. The incremental contribution of clinical breast examination to invasive cancer detection in a mammography screening program. Am J Roentgenol. 2012;184(2):428-32.

31. Huang Y, Zhou K, Li H, Wang A, Li J, Pang Y, Wang Q, Huang R, Fu L, Kang $M$. Knowledge, attitudes, and behaviour regarding breast cancer screening among women from different socio-economic regions in Southwest China: a cross-sectional study. Asian Pac J Cancer Prev. 2011;12(1):203-9.

32. Wang B, He M, Wang L, Engelgau MM, Zhao W, Wang L. Breast cancer screening among adult women in China, 2010. J Pre Chronic DiS. 2013;10:E183.

33. Miao M, Liu GY, Ying Z, Di LF, Ji YJ, Lv LL, Chen YY, Peng WJ, Zhu JR, Bao PP. Performance of breast cancer screening methods and modality among Chinese women: a report from a society-based breast screening program (SBSP) in shanghai. Springer Plus. 2013;2(1):276-276.

34. Sinicrope PS, Patten CA, Morgenthaler SB, Almquist JR, Smith CM, Beebe TJ, Jacobsen SJ, Vachon CM. Healthy Women's motivators and barriers to participation in a breast cancer cohort study: a qualitative study. Ann Epidemiol. 2009;19(7):484-93.

35. Molina Y, Hohl SD, Ko LK, Rodriguez EA, Thompson B, Beresford SAA. Understanding the patient-provider communication needs and experiences of Latina and non-Latina white women following an abnormal mammogram. J Cancer Educ. 2014;29(4):781-9.

36. Pace $L E$, Keating NL. A systematic assessment of benefits and risks to guide breast cancer screening decisions. JAMA. 2014;311(13):1327-35.

37. Anderson BO, Yip CH, Smith RA, Shyyan R, Sener SF, Eniu A, Carlson RW, Azavedo E, Harford J. Guideline implementation for breast healthcare in low-income and middle-income countries: overview of the breast health global initiative global summit 2007. Cancer. 2008;113(Suppl 8):2221-43.

38. Allen JD, Shelton RC, Harden E, Goldman RE. Follow-up of abnormal screening mammograms among low-income ethnically diverse women: findings from a qualitative study. Patient Educ Couns. 2008;72(2):283-92.

39. Arrospide A, Rue M, van Ravesteyn NT, Comas M, Larrañaga N, Sarriugarte G, Mar J. Evaluation of health benefits and harms of the breast cancer screening programme in the Basque Country using discrete event simulation. BMC Cancer. 2015;15(1):671.
40. Independent UK Panel on Breast Cancer Screening. The benefits and harms of breast cancer screening: an independent review. Lancet. 2012;380(9855): 1778-86.

41. Karnon J. Alternative decision modelling techniques for the evaluation of health care technologies: Markov processes versus discrete event simulation. Health Econ. 2003;12(10):837-48.

42. Simpson KN, Strassburger A, Jones WJ, Dietz B, Rajagopalan R. Comparison of Markov model and discrete-event simulation techniques for HIV. PharmacoEconomics. 2009;27(2):159-65.

43. Zheng S, Bai JQ, Li J, Li J, Fan JH, Pang Y, et al. The pathologic characteristics of breast cancer in China and its shift during 1999-2008: a national-wide multicenter cross-sectional image over 10 years. Int J Cancer. 2012;131(11):2622-31.

44. Huang ZZ, Chen WQ, Chun-Xiao WU, Zheng RS, Chen JG, Yang NN, Ning W, Zhang SW. Incidence and mortality of female breast cancer in China - a report from 32 Chinese cancer registries, 2003-2007. Tumor. 2012;32(6):435-9.

\section{Submit your next manuscript to BioMed Central and we will help you at every step:}

- We accept pre-submission inquiries

- Our selector tool helps you to find the most relevant journal

- We provide round the clock customer support

- Convenient online submission

- Thorough peer review

- Inclusion in PubMed and all major indexing services

- Maximum visibility for your research

Submit your manuscript at www.biomedcentral.com/submit
) Biomed Central 